\title{
A Comparative Insight into the Incidence of Steven Johnson Syndrome/ Toxic Epidermal Necrolyis among the Immunocompromized Patient Populace of Eastern India with a Distinctive Emphasis on the Possible Association of Human Cytomegalovirus
}

Aroni Chatterjee ${ }^{1}$, Indranil Thakur ${ }^{2}$, Sabbir Ansari" ${ }^{1 \#}$, Rajendra Prasad Chatterjee ${ }^{1 \#}$, Rathindranath Sarkar $^{2}$, Shuvashish Kamal Guha ${ }^{3}$ and Nilanjan Chakraborty ${ }^{1 *}$

${ }^{1}$ ICMR Virus Unit, Kolkata, India

${ }^{2}$ Calcutta Medical College and Hospital, Kolkata, India

${ }^{3}$ ART Centre, Virology Department, School of Tropical Medicine College and Hospital, Kolkata, India

\#Both the authors contributed equally

\begin{abstract}
Stevens-Johnson syndrome (SJS) and its more advanced form, Toxic Epidermal Necrolysis (TEN) are severe adverse cutaneous reactions that predominantly involve skin and mucous membranes. In view of the current dearth of documented knowledge, this study the first of its kind from India was designed to categorically distinguish and compare the different associated factors and clinical manifestations relevant to the development of SJS/TEN syndrome among the immunocompromised (Human Immunodeficiency Virus 1 seropositive) patients in Eastern India. 16 out of 29 patients $(55.1 \%)$ were found to be suffering from drug induced SJS or TEN, while the rest $(44.8 \%)$ had severe pathogenic involvements. Neviraprine use was found to be the major cause among drug involved SJS $(53.8 \%)$ and TEN $(66.66 \%)$ cases followed by allopurinol use. The frequency of incidence of kidney disease $(67 \%$ in SJS and $54 \%$ in TEN) and neurological impairment (42\% SJS and 37\%TEN) was found to be significantly higher among the SJS patients whereas that of hepatitis (38\% SJS and $47 \%$ TEN) , ocular dysfunction ( $49 \%$ SJS and $63 \%$ TEN) and pulmonary dysfunction ( $47 \%$ SJS and $53 \%$ TEN) were higher among the TEN patients. This study also had another prominent motive, which is to elucidate the possible role of human cytomegalovirus in triggering the exfoliative inflammatory disease conditions among these patients. The incidence rate of SGPT and SGOT were significantly higher in TEN patients than in SJS $(p=0.001$ and $p=0.002)$. Mean sodium level in blood was within normal range in both the groups whereas potassium and chloride levels were much higher than normal Out of the 29 HIV seropositive patients with SJS/TEN we studied, only $4(13.7 \%)$ had an active HCMV infection. In detailed study of the associated laboratory and clinical parameters, cytokine analysis profile, Immuno-histologic findings and rigorous analysis of the investigation reports identified $\mathrm{HCMV}$ infection as the probable trigger behind SJS/TEN development in these patients.
\end{abstract}

Keywords: Steven Johnson syndrome; Toxic epidermal necrolysis; Human immuno deficiency virus 1; Human cytomegalovirus

Abbreviations: SJS: Steven Johnson syndrome; TEN: Toxic Epidermal Necrolysis, HIV 1: Human Immunodeficiency Virus 1, HCMV: Human Cytomegalovirus

\section{Introduction}

Stevens-Johnson syndrome (SJS) and its more advanced form, toxic epidermal necrolysis (TEN) are severe adverse exfoliative cutaneous reactions that predominantly involve skin and mucous membranes. They are characterized by mucocutaneous tenderness, erythematous macules, hemorrhagic erosions, mucous membrane erosion and more or less severe epidermal detachment presenting as blisters and areas of denuded skin. Currently TEN and SJS are considered to be two ends of a spectrum of severe epidermolytic adverse cutaneous reactions, differing only by their extent of skin detachment [1]. The diagnosis of SJS/TEN was based on Bastuji-Garin criteria [2]. The international classification of SJS/TEN is based on the body surface area (BSA) involved: SJS involves $<10 \%$ of BSA; TEN involves $>30 \%$; and there is an overlap in definitions with involvement of 10-30\%. Mortality associated with SIS and TEN varies $10 \%$ to $50 \%$ worldwide. Common causes of death include septic shock, hypovolaemic shock, acute renal failure and fulminant hepatitis [3]. Drugs are assumed to be the main cause of SJS/TEN, but many infectious pathogens have also been documented as important causes. In recent years many people are working towards evaluating the proper role of infectious agents in inducing Steven
Johnson syndrome/Toxic epidermal necrolysis among differentially infected patients. Immunocompromized patients like those living with an active HIV infection happens to be a credible group for this kind of study [3,4]. A few cases have already been documented in this respect. Several drugs are at high risk of inducing TEN/SJS including nevirapine, allopurinol, quinolones, fluconazole etc. Diagnosis of TEN/ SJS relies mainly on clinical signs together with histological analysis of skin biopsy showing typical full thickness epidermal necrolysis due to extensive keratinocyte apoptosis [5]. An immunological response involving CD8+ T lymphocytes is perhaps the most likely explanation for the pathogenesis of SJS/TEN [6]. Other potential factors are the causative drug's inherent properties or chemical structure, type of pathogen involved, patient's physiological and immunological status

${ }^{*}$ Corresponding author: Nilanjan Chakraborty, PhD, ICMR Virus Unit, 57, Dr. S.C Banerjee road, Beliaghata, Kolkata-700010, India; Tel: 91-33-9163785518; E-mail: nilanjanchakraborty@ymail.com

Received June 02, 2017; Accepted June 24, 2017; Published June 29, 2017

Citation: Chatterjee A, Thakur I, Ansari S, Chatterjee RP, Sarkar R, et al. (2017) A Comparative Insight into the Incidence of Steven Johnson Syndrome/Toxic Epidermal Necrolyis among the Immunocompromized Patient Populace of Eastern India with a Distinctive Emphasis on the Possible Association of Human Cytomegalovirus. J AIDS Clin Res 8: 706. doi: 10.4172/2155-6113.1000706

Copyright: (c) 2017 Chatterjee A, et al. This is an open-access article distributed under the terms of the Creative Commons Attribution License, which permits unrestricted use, distribution, and reproduction in any medium, provided the original author and source are credited. 
Citation: Chatterjee A, Thakur I, Ansari S, Chatterjee RP, Sarkar R, et al. (2017) A Comparative Insight into the Incidence of Steven Johnson Syndrome/ Toxic Epidermal Necrolyis among the Immunocompromized Patient Populace of Eastern India with a Distinctive Emphasis on the Possible Association of Human Cytomegalovirus. J AIDS Clin Res 8: 706. doi: 10.4172/2155-6113.1000706

Page 2 of 9

such as HIV status and CD4+ count, etc. [7,8]. Affected individuals with severe SJS/TEN can likely be also genetically predisposed to develop severe cutaneous reactions governed by the type and interaction of the major histocompatibility complex molecules on their leukocyte cell surface [9]. SJS and TEN cases associated with mycoplasma and chlamydophila infections have been observed in few cases and has been documented effectively $[10,11]$.The association between viral infection and cutaneous drug eruption has been well documented in infectious mononucleosis cases caused by Epstein-Barr virus (EBV) and HSV, in which ampicillin rash is frequently observed [12]. In addition to EBV, human herpesvirus (HHV) -6 and cytomegalovirus (CMV; HHV-5) have also been reported as causative viruses of infectious cutaneous mononucleosis syndrome and Drug-induced hypersensitivity syndrome (DIHS) [13]. Cytomegalovirus reactivation was also documented in a few patients with SJS and DIHS [14]. In view of the current dearth and inadequacy of documented knowledge, this study the first of its kind from India was designed to categorically distinguish and compare the different associated factors and clinical manifestations relevant to the development of SJS/TEN syndrome among the immunocompromised patients in Eastern India. At the same time this study also tries to implicate and elucidate the possible role of human cytomegalovirus in triggering these exfoliative inflammatory disease conditions among these patients. Although an increase in serum antibodies to HCMV has been observed in case of some SJS patients, the active infection of HHV-6 and HCMV (HHV-5) has never been studied and correlated with the development of TEN and SJS $[14,15]$. Hence it is worthy to point out that the relevance of HCMV and other related viral infections in association with their prevalence and semblance in case of SJS/TEN development is surely to provide a better insight in the understanding of this disease scenario.

\section{Materials and Methods}

\section{Patient selection}

We focused our study on collecting cases of only HIV 1 (Human Immunodeficiency Virus 1) seropositive patients suffering from SJS or TEN, who were admitted to the emergency unit of Kolkata medical college and hospital between January 2014 and January 2017. The diagnosis of SJS/TEN was based on Bastuji-Garin criteria.

Inclusion criteria: The inclusion criteria for the patients are as follows, for SJS, symptoms should include acute conditions characterized by mucous membrane erosions and skin lesions (described as macules, atypical target-like lesions, bulla, or erosions) with a maximum epidermal detachment of less than equal to $10 \%$ of the total body surface area (BSA) ; and for TEN the symptoms should include a maximum epidermal detachment of greater than equal to $30 \%$ of the BSA in addition to the symptoms above. Cases that were classified as overlap of SJS/TEN according to the Bastuji-Garin criteria with a maximum epidermal detachment of 11-29\% of the BSA involvement were included as SJS in this study. Among the HIV seropositive subjects screened, a total of 29 patients suffering from SJS or TEN were selected for our study. Out of these selected patients those cases which were found to have a direct relation with acute HCMV infection or in which the condition seemed to be induced by the virus were selected for our further analysis.

Exclusion criteria: Non HIV patients with or without SJS or TEN were excluded from this study.

Control samples: HIV positive patients without SJS/TEN and HIV HCMV co-infected patients without SJS/TEN were selected as controls.

\section{Patient data collection}

The following data were collected: Demographic information (age and sex) , relevant past medical history and coexisting conditions, clinical laboratory parameters, antecedent use of medications, time between the first causative drug intake and the onset of symptoms, maximum epidermal detachment as a percentage of BSA (Body surface area), SCORTEN (Score of toxic epidermal necrolysis value) , presence and extent of mucous membrane involvement, secondary pathogenic infections, HIV viral load, CD4+ T cell count, laboratory data, results of patch testing and lymphocyte stimulation tests using suspected drugs, organs involvement, presenting complications, treatment regimens, plasmapheresis, the time from the initiation of therapy to control of the lesions (a halt in necrolytic progression and subsequent reepithelization), duration of hospital stay and mortality. The case notes, charts, investigation results and treatment records of these patients were retrospectively reviewed and statistically analyzed.

Sample collection: EDTA (Ethylenediaminetetraacetic acid) anti coagulated peripheral blood $(5-10 \mathrm{~mL})$ was collected from patients in vacutainer tubes, processed immediately and serum was separated from the whole blood by centrifugation (1000x g for $10 \mathrm{~min}$ ). Serum was quickly frozen at $-80^{\circ} \mathrm{C}$ and stored until processed.

DNA isolation from serum: DNA was isolated from the blood serum using QIamp DNA blood Mini Kit (Qiagen Inc., Hilden, Germany) as per manufacturer's protocol and remaining serum was kept at $-80^{\circ} \mathrm{C}$.

\section{Serology and molecular diagnosis of Human Cytomegalovirus (HCMV)}

CMV IgG and IgM ELISA: Serum anti-CMV status was determined by a commercially available test kit, CMV IgM, IgG ELISA Test kit supplied by EQUIPAR (Soronno, Italy) . It was used to detect antibodies against the CMV-IE1 and CMV-pp65mII.

Qualitative PCR: We used Cinnagen CMV detection PCR kit (Sinaclon bioscience Co., Iran) for viral gene detection. This kit contains PCR master mix, Taq DNA Polymerase and positive control for the detection of HCMV positive sample. The reaction mixture and PCR conditions were maintained as given in the manufacturer's protocol. The presence of $222 \mathrm{bp}$ gene fragments indicates positive test.

Real time quantitative PCR for viral load measurement: We designed the sequence of primers in the UL 75 region of HCMV. The forward and reverse primers of UL 75 were 5/- CCT TGC GTG TCG TCG TAT TCT AGC-3/ and 5/-GCC TCA TCA TCA CCC AAA CGG ACA G-3/ respectively. For each $20 \mu \mathrm{L}$ PCR reaction mixture, $10 \mu \mathrm{L}$ of maxima SYBR green qPCR 2X master mix (Thermo Fisher Scientific, Waltham, Massachusetts, USA) , 0.5 pmol of each forward and reverse primer, $3.6 \mu \mathrm{L}$ sterile water and $5 \mu \mathrm{L}$ of DNA samples were used. For each sample, the real time PCR was performed in triplicate in 96 well plates. Thermal cycling was initiated with a denaturation step of $95^{\circ} \mathrm{C}$ for $10 \mathrm{~min}$. It was followed by $45 \mathrm{cycles}$ of $95^{\circ} \mathrm{C}$ for $30 \mathrm{~s}$ and $57^{\circ} \mathrm{C}$ for $30 \mathrm{~s}, 72^{\circ} \mathrm{C}$ for $15 \mathrm{~s}$ and final extension at $72^{\circ} \mathrm{C}$ for $5 \mathrm{~min}$. Melt curve analysis was included in real time PCR protocol. Following conditions will be used for melt curve $55^{\circ} \mathrm{C}$ to $95^{\circ} \mathrm{C}$ : Increment $1^{\circ} \mathrm{C}$ for $1 \mathrm{~min}$.

HCMV Qualitative PCR with viral DNA from epidermal tissue samples: DNA was isolated from homogenized epidermal and dermal tissues of patients using Qiagen DNA minikit (Qiagen, Hilden, Germany) as per manufacturer's protocol. Cinnagen CMV detection PCR kit (Sinaclon bioscience Co., Iran) was used for viral DNA detection. 
Citation: Chatterjee A, Thakur I, Ansari S, Chatterjee RP, Sarkar R, et al. (2017) A Comparative Insight into the Incidence of Steven Johnson Syndrome/ Toxic Epidermal Necrolyis among the Immunocompromized Patient Populace of Eastern India with a Distinctive Emphasis on the Possible Association of Human Cytomegalovirus. J AIDS Clin Res 8: 706. doi: 10.4172/2155-6113.1000706

Page 3 of 9

Cytokine assay from serum: Serum TNF- $\alpha$, IFN- $\gamma$, IL2, IL-6 and IL-8 levels were measured by using enzyme-linked immunosorbent assay (ELISA) technique kits (Abcam biotech co., Cambridge, UK). These assays detected only human cytokines and at very low serum concentrations. ELISA was performed as per manufacturer's protocol.

\section{Statistical analysis}

Results are expressed as mean \pm standard deviation, unless otherwise indicated. Kruskal-wallis test for generating comparisons was performed. Differences between groups were compared by unpaired t-testing and one way analysis of variance. Cox regression analysis was performed to analyze associations between the time from drug therapy initiation to control of the lesions, the mean dosage of corticosteroids used and other selective variables. The level of significance ( $P$ value) was set at $5 \%$. All $\mathrm{P}$ values are two tailed. All statistical analyses were carried out with SPSS software (version 14.0; SPSS, Inc., Chicago, IL, USA) . Post-hoc sample size calculation analysis gave a power value of $62.2 \%$ with 29 subjects and alpha value 0.05 .

\section{Ethical considerations}

The present study and methodologies were approved by the scientific advisory committees (SAC) and certified by Institutional Ethics Committee (IEC) of ICMR Virus Unit, Kolkata as well as all the respective hospitals. Written informed consents were taken after explaining all associated positive and negative aspects regarding the study to each participating patient in a language that they understand clearly (Bengali, A local language; Hindi, National language; and English, International language). Our study included clinical examination, medical questionnaires, personal family history, occupation, social and professional conditions. Confidentiality of the provided information was maintained properly as per the standard national guidelines in a similar manner ensuring that they clearly understand.

\section{Results}

\section{Patient's demographics and clinical data associated with causes of SJS/TEN development}

Twenty nine HIV positive patients were selected in this 3 years study of which 23 patients suffered from Steven Johnson syndrome (SIS) and 6 from Toxic Epidermal Necrolysis (TEN) . The age of the SJS subjects ranged from 21 to 77 years and that of the TEN patients from 32 to 73 . The male proportion was higher in both the groups, 3.1:1 (18:5) in SJS cases and 2:1 (4:2) in TEN cases. The age group and gender wise distribution of the cases are presented in Figure 1.

Involvement of drugs and infectious agents that were considered to be the probable cause of SJS/TEN in these patients are listed in Table 1. $56.5 \%$ of the HIV positive patients developed SJS due to drugs whereas in $43.4 \%$ of the patients the syndrome was due to the involvement of various infectious agents. In case of TEN both drug use and infectious disease involvement attributes to $50 \%$ of the causative cases. Neviraprine use was found to be the major cause among drug involved SJS (53.8\%) and TEN (66.66\%) cases followed by allopurinol use. In cases of infectious disease involvement associated with the development of SJS mycobacterium was found in $40 \%$ of the cases followed by human cytomegalovirus in $20 \%$ of cases. Other viral and bacterial infections were observed in about $10 \%$ of cases. In case of TEN, Mycobacterium sp., Cytomegalovirus, Acinetobacter sp. and Enterobacteriacae were found to be associated in $33.33 \%$ cases each.

\section{SJS/IEN cases induced by drugs}

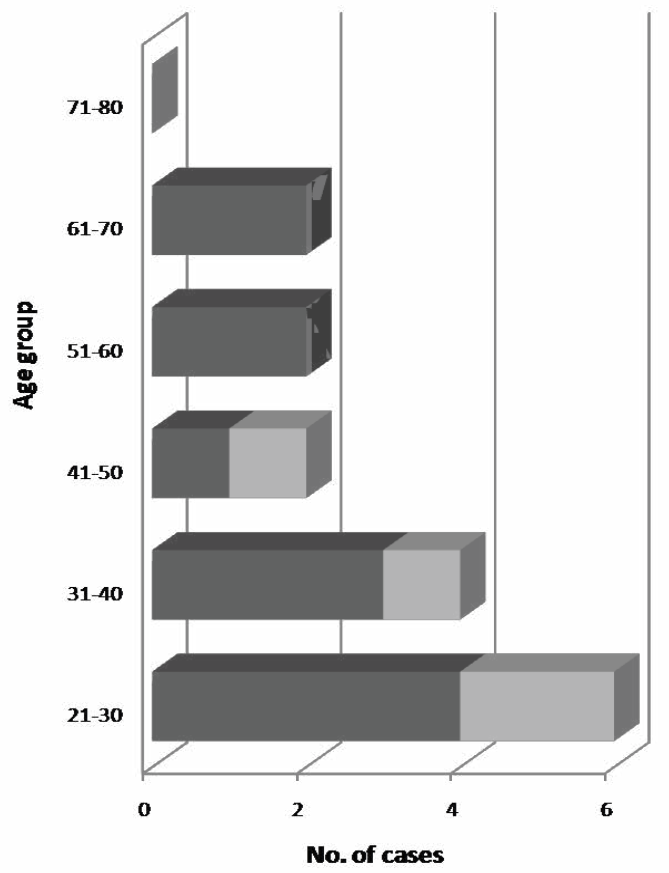

SJS/TEN cases associated with infectious diseases involvement

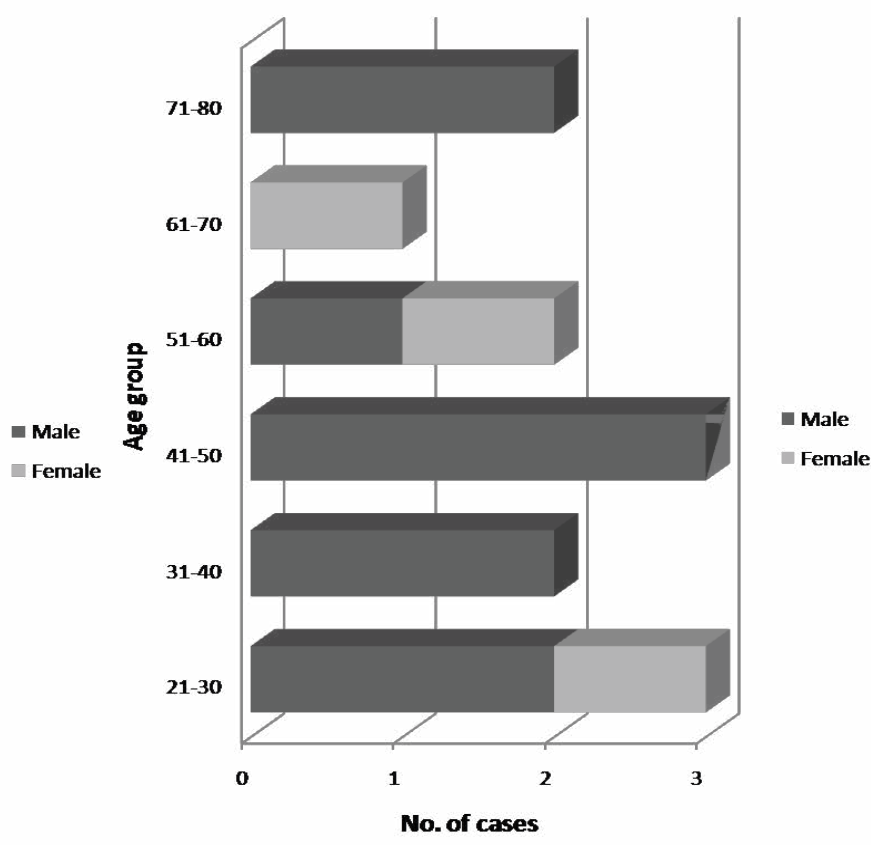

Figure 1: Classification of the selected SJS/TEN cases based on age group and gender. 
Citation: Chatterjee A, Thakur I, Ansari S, Chatterjee RP, Sarkar R, et al. (2017) A Comparative Insight into the Incidence of Steven Johnson Syndrome/ Toxic Epidermal Necrolyis among the Immunocompromized Patient Populace of Eastern India with a Distinctive Emphasis on the Possible Association of Human Cytomegalovirus. J AIDS Clin Res 8: 706. doi: 10.4172/2155-6113.1000706

Page 4 of 9

\begin{tabular}{|c|c|c|c|c|}
\hline Parameters & & SJS & TEN & \\
\hline Gender & M & $\mathbf{F}$ & M & $\mathbf{F}$ \\
\hline No. of cases $(n)$ & 18 & 5 & 4 & 2 \\
\hline Mean age (Years) & $46.5(21-77)$ & $47.2(28-64)$ & $53.5(32-71)$ & $62(52,73)$ \\
\hline Drug involvement (n) & $10(55 \%)$ & $3(60 \%)$ & $2(50 \%)$ & $1(50 \%)$ \\
\hline Anti-HIV (Neviraprine) & $5(50 \%)$ & $2(66 \%)$ & $1(50 \%)$ & $1(100 \%)$ \\
\hline Antipodagrics (Allopurinol) & $2(20 \%)$ & $1(33 \%)$ & $1(50 \%)$ & 0 \\
\hline Anticonvulsants & $2(20 \%)$ & 0 & 0 & $1(100 \%)$ \\
\hline Antibiotics & 0 & 0 & 0 & 0 \\
\hline NSAID's & $1(10 \%)$ & 0 & $1(50 \%)$ & 0 \\
\hline Infectious disease involvement (n) & $8(44 \%)$ & $2(40 \%)$ & $2(50 \%)$ & $1(50 \%)$ \\
\hline Mycobacterium & $3(37 \%)$ & $1(50 \%)$ & $1(50 \%)$ & 0 \\
\hline Adenovirus & 0 & 0 & 0 & 0 \\
\hline Epstein Barr Virus & $1(12.5 \%)$ & 0 & 0 & 0 \\
\hline Herpes Simplex Virus & 0 & $1(50 \%)$ & 0 & 0 \\
\hline Human Cytomegalovirus & $2(25 \%)$ & $1(50 \%)$ & $1(50 \%)$ & 0 \\
\hline Staphylococcus sp. & 0 & 0 & 0 & 0 \\
\hline Enterobacteriacae & $1(12.5 \%)$ & 0 & 0 & $1(100 \%)$ \\
\hline Pseudomonas sp. & $1(12.5 \%)$ & 0 & 0 & 0 \\
\hline Acinetobacter sp. & 0 & $1(50 \%)$ & $1(50 \%)$ & 0 \\
\hline
\end{tabular}

Table 1: Demographics of the selected HIV sero-positive patient group suffering from SJS/TEN.

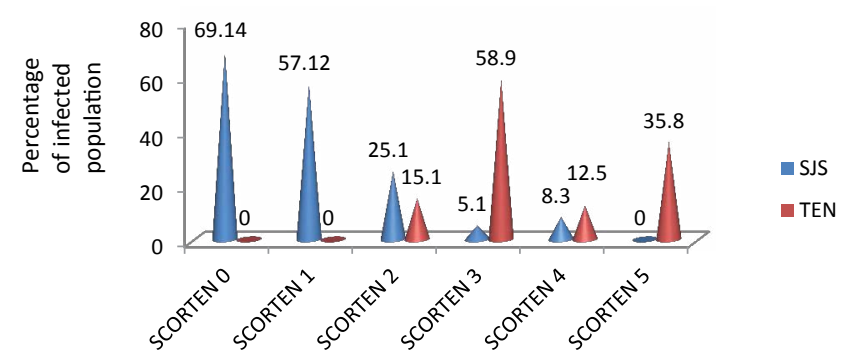

Figure 2: Severity of disease classified by the SCORTEN scale in the HIV patients with SJS and TEN.

SCORTEN: Score of Toxic Epidermal Necrolysis; SJS: Stevens-Johnson Syndrome; TEN: Toxic Epidermal Necrolysis

\section{Disease severity}

The SCORTEN (Score of toxic epidermal necrolysis) scoring system was used to grade the severity of these diseases. The majority of the patients in the SJS group (50.45\%) had a score of 0 to 2 while the majority of the TEN groups (48.7\%) had a score of 3 and 5 . A classification of the patient population according to the SCORTEN scale has been provided in Figure 2 .

\section{Comparison of clinical laboratory parameters among SJS and TEN groups of patients at the time of admission}

Significant HIV viral load was observed in all the patients. CD4+ $\mathrm{T}$ cell count was low and existed on the range of 32-118 among the patients. No significant difference was observed in the CD4 count among the SJS and TEN groups of patients $(p=0.328)$. The mean WBC count and mean haemoglobin level were within normal range among both the groups. Mean platelet count was below normal in both the groups indicating acute thrombocytopenia with significant higher incidence rate among TEN patients $(\mathrm{p}=0.002)$. Blood urea nitrogen level was in the upper side of the normal range whereas the creatinine level was higher in both the SJS and TEN groups of patients. This indicates towards the onset of critical renal dysfunctioning. The

\begin{tabular}{|c|c|c|}
\hline Parameters & $\begin{array}{l}\text { SJS }(n=23) \\
\text { Mean Value }\end{array}$ & $\begin{array}{l}\text { TEN }(n=6) \\
\text { Mean Value }\end{array}$ \\
\hline Duration of Fever (days) & 4.79 & 5.1 \\
\hline HIV viral load & $7.2 \times 10^{4}$ & $8.9 \times 10^{4}$ \\
\hline CD4 count & 98 & 92 \\
\hline CD4:CD8 & 0.06 & 0.25 \\
\hline WBC $(/ \mu \mathrm{ll})$ & 9968 & 8300 \\
\hline Hemoglobin (g/dl) & 11.8 & 12.5 \\
\hline Platelets $(/ \mu 1 \times 1000)$ & 142.1 & 139.2 \\
\hline C- reactive protein (mg/dl) & 3.38 & 4.33 \\
\hline Blood urea nitrogen $(\mathrm{mg} / \mathrm{dl})$ & 19.8 & 18.2 \\
\hline Serum Creatinine (mg/dl) & 1.2 & 1.5 \\
\hline SGOT (IU/L) & 57.2 & 81 \\
\hline SGPT (IU/L) & 59.35 & 103.2 \\
\hline Serum albumin (gm/l) & 18.1 & 15.3 \\
\hline Total serum billirubin (gm/l) & 0.6 & 0.5 \\
\hline Alkaline phosphatase (U/L) & 140.9 & 154.1 \\
\hline Sodium (mEq/l) & 139.4 & 137.5 \\
\hline Potassium (mEq/l) & 5.1 & 5.7 \\
\hline Chloride (mEq/l) & 107.8 & 108.2 \\
\hline Time to response to therapy (Days) & 8.45 & 10.68 \\
\hline Total hospital stays (Days) & 20.12 & 27.6 \\
\hline
\end{tabular}

Table 2: Analysis of the mean laboratory parameters associated with StevensJohnson syndrome and Toxic Epidermal Necrolysis in the selected

albumin and total billirubin levels were both significantly lower than normal range among both the group of patients indicating the case of hypoproteinemia. Liver enzymes alanine transaminase (SGPT) and aspartate transaminase (SGOT) both were found to be elevated in both the groups indicating severe liver derangement. However the incidence rate of SGPT and SGOT were significantly higher in TEN patients than in SJS ( $p=0.001$ and $p=0.002$ ). Mean sodium level in blood was within normal range in both the groups whereas potassium and chloride levels were much higher than normal, indicating the prevalence of a hyperkalemic and hyperchloremic condition. A detailed analysis report taking account the mean value of all the clinical parameters is presented in Table 2. 
Citation: Chatterjee A, Thakur I, Ansari S, Chatterjee RP, Sarkar R, et al. (2017) A Comparative Insight into the Incidence of Steven Johnson Syndrome/ Toxic Epidermal Necrolyis among the Immunocompromized Patient Populace of Eastern India with a Distinctive Emphasis on the Possible Association of Human Cytomegalovirus. J AIDS Clin Res 8: 706. doi: 10.4172/2155-6113.1000706

Comparison of physiological complications by assessment of mean clinical marker levels in blood among the SJS and TEN groups of HIV positive patients

Some of the major complications associated with SIS/TEN have been followed during this study that includes hypoproteinemia, hepatic derangement with higher than normal levels of liver enzymes, renal dysfunction with elevated urea or creatinine levels, hypokalemia and hypochloremia. A detailed week wise distribution analysis of the conditions has been presented in Figure 3. Hypoproteinemia was a general complication observed in case of both SJS and TEN patients predominantly from the very first week of disease onset as visible from the low serum concentrations of albumin and billirubin. Serum albumin level increased towards normal value by $2^{\text {nd }}$ week but again decreased considerably below normal in the following weeks. The incidence rate of hypoproteinemia was significantly higher in SJS patients than in TEN $(\mathrm{P}=0.002)$. Hepatic derangement with elevation of the liver enzymes (Serum glutamate pyruvate transferase (SGPT) and Serum glutamate oxaloacetate transferase (SGOT) was another common complication visible from the first week of disease onset and with no significant difference in the incidence rate among the SJS and TEN patients $(\mathrm{P}=0.138)$. Serum urea and blood sodium levels were towards the upper side of normal range in the very first week but decreased after that. The difference in their incidence rate and variation was not quite significant among the two group of patients $(\mathrm{P}=0.223)$. Serum creatinine level was slightly elevated from normal range starting from the first week after onset followed by periodic variations. The difference in the incidence rate was significantly higher in case of TEN patients $(\mathrm{P}=0.01)$. Hypochloremia was observed in both groups of patients with significant decreased level during $2^{\text {nd }}$ and $3^{\text {rd }}$ weeks after onset. There was no significant difference in its incidence among SJS and TEN patients though $(\mathrm{P}=0.228)$.

Association of underlying diseases and complications with SJS/TEN development in the selected HIV positive patients

Chronic kidney disease (67\% SJS and 54\% TEN) , Ocular dysfunction (49\% SJS and 63\% TEN) and pulmonary dysfunction $(47 \%$ SJS and 53\% TEN) were the major observed complications associated with the SJS/TEN patients. These were followed by other complications like neurological impairment (42\% SJS and 37\%TEN), Hepatitis (38\% SJS and 47\% TEN) and Allergy (37\% SJS and 41\% TEN). The frequency of incidence of kidney disease and ocular dysfunction was significantly higher among the SJS patients $(\mathrm{P}=0.001$ and $\mathrm{P}=0.01$, respectively) whereas that of hepatitis and pulmonary dysfunction were higher among the TEN patients $(\mathrm{P}=0.002$ and $\mathrm{P}=0.03$, respectively) . No significant difference was observed in the occurrence of the other complications among the two groups of patients. A detailed analysis has been provided in Figure 4A.

Skin or cutaneous lesions ranged from mild to severe and observed in both SJS ( $72 \%$ cases) and TEN (79\% cases) groups of patients. A detailed comparative analysis has been provided in Figure 4B. There was no remarkable difference in the frequency of its incidence among the two groups. The ocular mucous lesions were observed in $87 \%$ of the TEN patients and $67 \%$ of the SJS patients; the oral mucous lesions were observed in $77 \%$ of SJS cases and $69 \%$ of the TEN patients. The
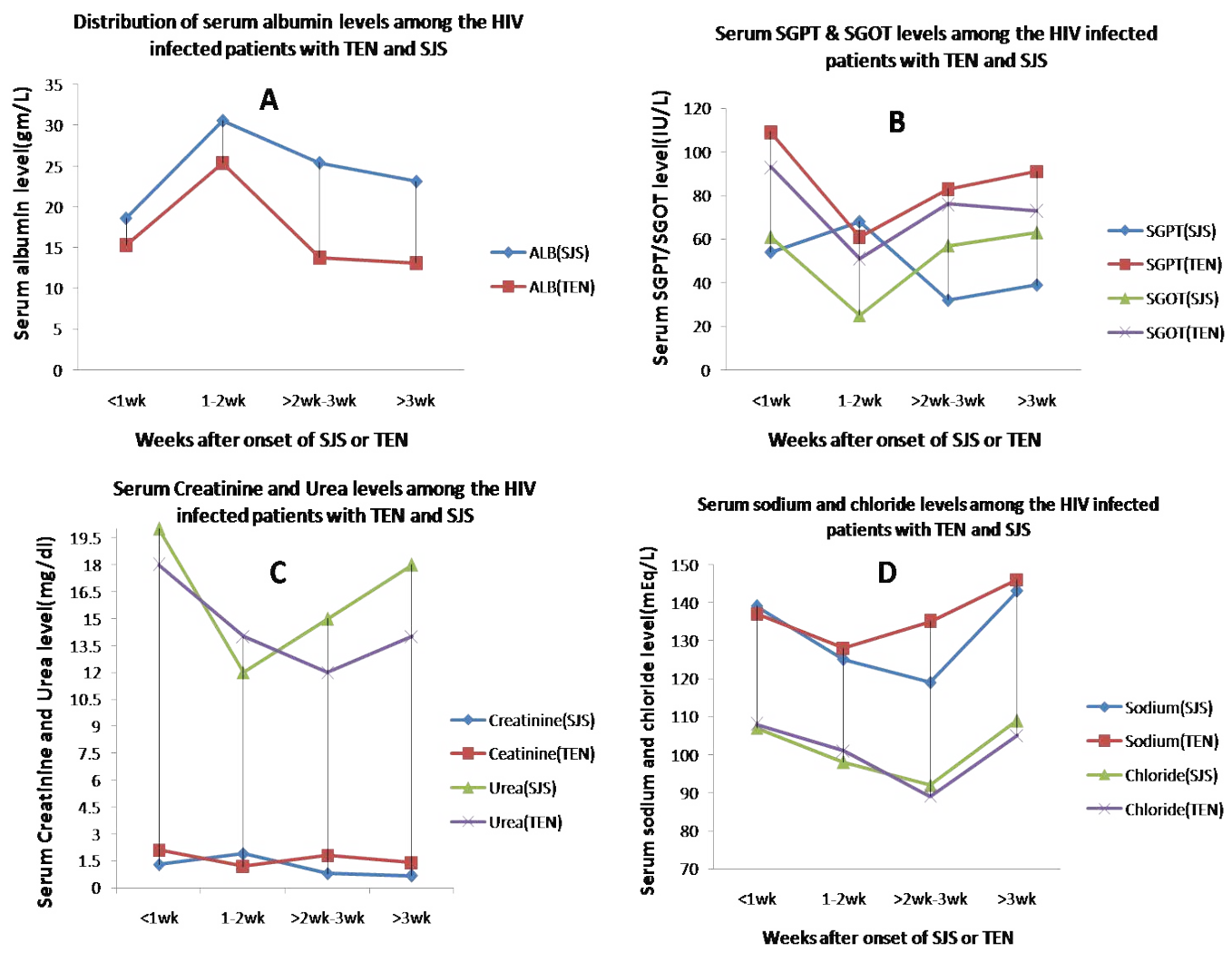

Weeks after onset of SIS or TEN

Figure 3: Week wise distribution in mean serum concentrations of various clinical factors among the patients with SJS and TEN depicting physiological complications; A- Hypoproteinemia, B- Hepatic involvement, C- Renal involvement, D- Hypochloremia. 
Citation: Chatterjee A, Thakur I, Ansari S, Chatterjee RP, Sarkar R, et al. (2017) A Comparative Insight into the Incidence of Steven Johnson Syndrome/ Toxic Epidermal Necrolyis among the Immunocompromized Patient Populace of Eastern India with a Distinctive Emphasis on the Possible Association of Human Cytomegalovirus. J AIDS Clin Res 8: 706. doi: 10.4172/2155-6113.1000706
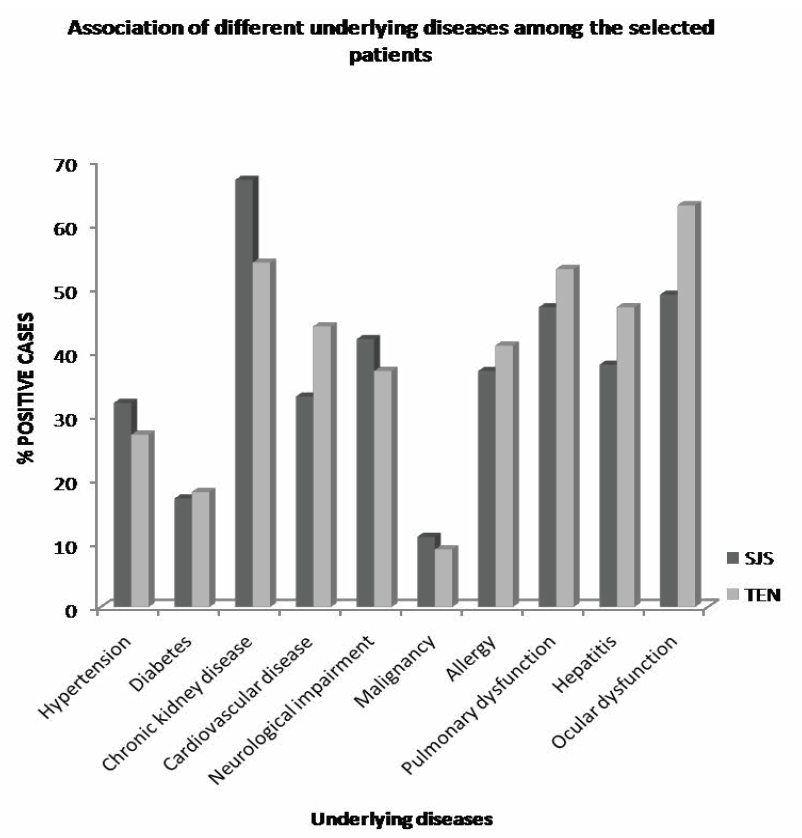
Skin and mucous membrane involvement among the selected
patients

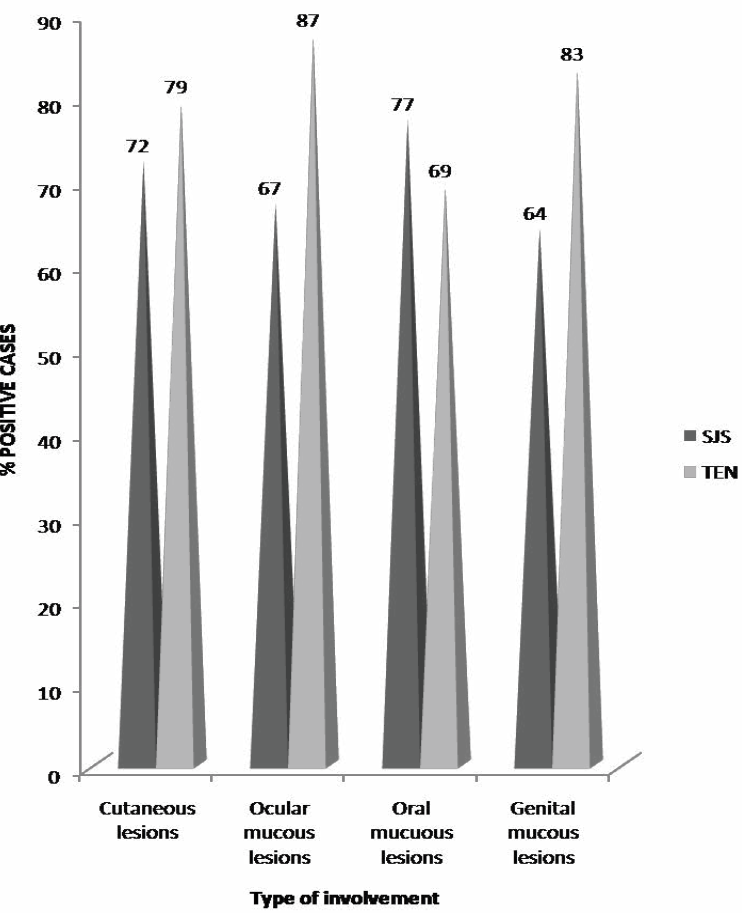

Figure 4: A- Comparative distribution of the different underlying diseases associated with SJS/TEN among the HIV seropositive patients; B- Comparison of Skin and mucous membrane involvement among the SJS/TEN patient groups.

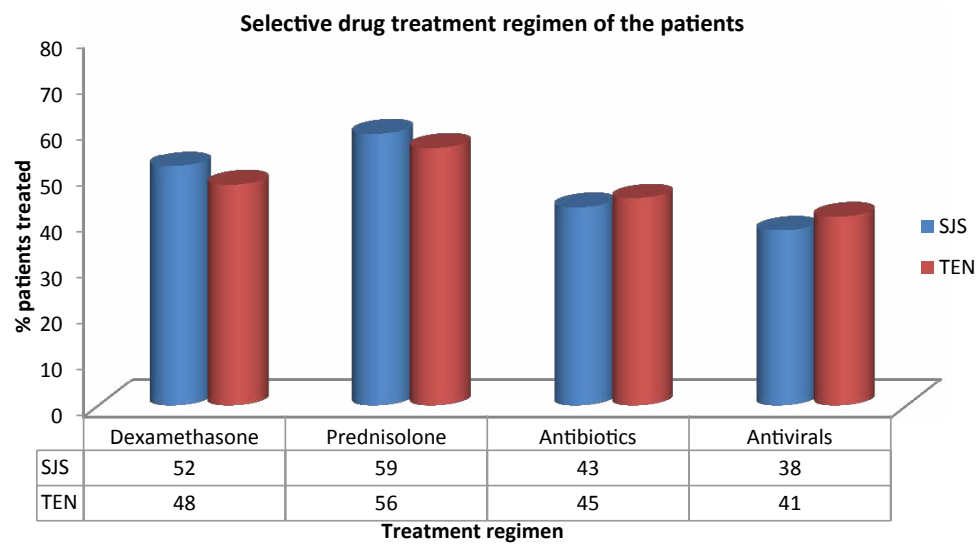

Figure 5: Selected drug treatment regime of the patients compared among the two groups.

frequency of incidence of ocular lesions were significantly higher in case of TEN patients compared to SJS patients $(\mathrm{P}=0.002)$ whereas the incidence rate of oral lesions were significantly higher in the case of SJS patients than TEN patients $(\mathrm{P}=0.01)$. Genital lesions were present in the patients from both the groups (64\% SJS and $83 \%$ TEN) with no significant difference in the frequency occurrence among them.

Selective drug treatment of the patients and estimating the association of drug therapy initiation with other selective variables

A total of $53.75 \%$ of the SJS/TEN patients received corticosteroid treatment. Intravenous dexamethosone was used in $50 \%$ cases whereas oral predinisolone was used in $57.5 \%$ cases. $44 \%$ of the total patients received antibiotic treatment whereas $39.5 \%$ of the patients received antiviral treatment. A detailed report of the drugs used with the percentage of patients treated has been provided in Figure 5.

To evaluate the associations between the times from drug therapy initiation to control of the lesions and the mean dosage of corticosteroids used as well as the other variables, Cox regression analysis was conducted. In this analysis the time from the initiation of therapy to the control of lesions was employed as dependent variable, whereas 
Citation: Chatterjee A, Thakur I, Ansari S, Chatterjee RP, Sarkar R, et al. (2017) A Comparative Insight into the Incidence of Steven Johnson Syndrome/ Toxic Epidermal Necrolyis among the Immunocompromized Patient Populace of Eastern India with a Distinctive Emphasis on the Possible Association of Human Cytomegalovirus. J AIDS Clin Res 8: 706. doi: 10.4172/2155-6113.1000706

Page 7 of 9

age, sex, SCORTEN value, mean corticosteroid dosage and pathogen involvement were selected as covariate (independent) variables. The results of the Cox regression analysis (Table 3) indicated that the time from drug therapy initiation to control of the lesions was significantly associated with age $\left(\beta_{\text {age }}=-0.024, \mathrm{P}_{\text {age }}=0.037\right)$ and with pathogen involvement $\left(\beta_{\text {pathogen }}=-0.336, \mathrm{P}_{\text {pathogen }}=0.016\right)$ in case of only SJS patients. However the associations of the dependent variable with the other covariate variables like SCORTEN score and corticosteroid treatment was statistically significant in case of both SJS and TEN patients $\left(\beta_{\text {SIS. }}\right.$ SCORTEN $=1.117, \mathrm{P}_{\text {SIS-SCORTEN }}=0.003 ; \beta_{\text {TEN-SCORTEN }}=0.050, \mathrm{P}_{\text {TEN }- \text { SCORTEN }}=0.043$; $\beta_{\text {SIS-Corticosteroid }}=0.001, \mathrm{P}_{\text {SS-Corticosteroid }}=0.046 ; \beta_{\text {TEN-Corticosteroid }}=-0.013, \mathrm{P}_{\text {TEN }}$ coricosteroid $=0.018)$. There was no significant association of the dependent variable with sex in case of both SJS and TEN patients.

\section{Comparative analysis of the clinical characteristics between the survivor and non-survivor patient groups}

Four patients in the TEN group (67\%) and three patients in the SJS group (13\%) succumbed during treatment. The overall mortality rate among the SJS/TEN patients were $24.1 \%$. The main causes of mortality include septicemia, renal failure, cardiac arrhythmia and respiratory failure. Comparison between the survival group and the non-survival group revealed that patient's age greater than 40 years, $20 \%$ body surface area involvement and involvement of all 3 mucosal areas are significant factors contributing to mortality $(\mathrm{P}=0.012, \mathrm{P}=0.001$ and $\mathrm{P}=0.004$, respectively). Hepatic dysfunctioning and blood stream infections also contributed significantly to the mortality among these patients ( $\mathrm{P}=0.014$ and $\mathrm{P}=0.004$, respectively) . There was no significant difference in SCORTEN score among the survival and non-survival groups $(\mathrm{P}=0.156)$. Corticosteroid use was much higher in case of the survival group compared to the non-survival group $(71.1 \%$ vs $10 \%$; $\mathrm{P}=0.016)$. A detailed comparative analysis of the different clinical characteristics between the survival and non-survival groups has been provided in Table 4

\section{Acute HCMV infection associated with development of SJS and TEN}

Out of the 29 SJS/TEN HIV patients studied, only four were diagnosed with acute HCMV infection. Three of the four patients were male and their mean age was 62.75 . Three of the patients were suffering from SJS and one with TEN. HCMV IgM ELISA and qualitative PCR gave positive results for each of the patients. HCMV viral load in serum was found to be quite high (mean- $4.63 \times 10^{6}$ ). These 4 patients were not under the action of any drug known to be a causative agent of mucocutaneous eruptions nor were they severely infected by any other pathogen. All the patients had very low CD4+ T cell count (Mean-51) , high CD8+T cell count and high HIV viral load in blood (Mean$\left.8.45 \times 10^{4}\right)$. Almost all these patients suffered from HCMV mediated

\begin{tabular}{|c|c|c|c|}
\hline Variable & Group & $\boldsymbol{\beta}$ & P-value \\
\hline Age & SJS & -0.024 & 0.037 \\
& TEN & -0.028 & 0.914 \\
\hline Sex & SJS & -0.568 & 0.280 \\
& TEN & -0.289 & 0.308 \\
\hline SCORTEN & SJS & 1.117 & 0.003 \\
& TEN & 0.050 & 0.043 \\
\hline Corticosteroid & SJS & 0.001 & 0.046 \\
dosage & TEN & -0.013 & 0.018 \\
\hline Pathogen & SJS & -0.336 & 0.016 \\
involvement & TEN & -0.106 & 0.14 \\
\hline
\end{tabular}

Table 3: Results of the Cox regression analysis showing associations between the time from drug therapy initiation to control of the lesions, the mean dosage of corticosteroids used and other selective variables.

\begin{tabular}{|c|c|c|c|}
\hline Variables & $\begin{array}{l}\text { Survival group (\%) } \\
\text { SJS /TEN }\end{array}$ & $\begin{array}{c}\text { Non-survival group (\%) } \\
\text { SJS/TEN }\end{array}$ & p-value \\
\hline \multicolumn{4}{|l|}{ Age } \\
\hline$<=40$ & 45 & 39 & 0.054 \\
\hline$>40$ & 28 & 59 & 0.012 \\
\hline \multicolumn{4}{|l|}{ Gender } \\
\hline Male & 41 & 71 & 0.210 \\
\hline Female & 63 & 47 & 0.321 \\
\hline $\begin{array}{c}\text { BSA involvement } \\
(>20 \%)\end{array}$ & 33 & 100 & 0.001 \\
\hline $\begin{array}{l}\text { Involvement of } 3 \\
\text { mucosal areas }\end{array}$ & 87.5 & 98 & 0.004 \\
\hline Oral mucosa & 97.5 & 100 & 0.047 \\
\hline Genital mucosa & 92.5 & 100 & 0.224 \\
\hline Optic mucosa & 88 & 100 & 0.317 \\
\hline Cutaneous lesions & 82.5 & 97.5 & 0.014 \\
\hline Renal dysfunction & 32 & 41 & 0.903 \\
\hline Hepatic dysfunction & 51 & 43 & 0.014 \\
\hline $\begin{array}{l}\text { Pulmonary } \\
\text { dysfunction }\end{array}$ & 22.5 & 37.5 & 0.572 \\
\hline Diabetes & 15 & 33.3 & 0.308 \\
\hline Malignancy & 12.5 & 28.5 & 0.901 \\
\hline $\begin{array}{l}\text { Cardiovascular } \\
\text { dysfunction }\end{array}$ & 21.5 & 32.5 & 0.152 \\
\hline $\begin{array}{l}\text { Blood urea (>15mg/ } \\
\text { dl) }\end{array}$ & 27 & 66 & 0.226 \\
\hline $\begin{array}{l}\text { Serum albumin } \\
(<20 \mathrm{~g} / \mathrm{l})\end{array}$ & 37.5 & 66 & 0.578 \\
\hline Corticosteroid & 71.1 & 10 & 0.016 \\
\hline Infections & 44 & 97.5 & 0.004 \\
\hline SCORTEN >2 & 21.5 & 73.5 & 0.156 \\
\hline Antibiotics use & 41 & 98 & 0.319 \\
\hline
\end{tabular}

Table 4: Results of univariate analysis of the clinical variables and health complications associated with survival and non-survival groups.

retinitis and hepatitis. Severe liver derangement (High SGPT and high SGOT value) along with cholestatis was also observed in all of them. Time of SJS/TEN symptom onset correlated with the symptomatic disease expression of HCMV infection. Treatment with intravenous gancyclovir greatly decreased HCMV pathogenesis resulting in a gradual reduction of muco-cutaneous exfoliative eruptions. One out of these four patients died after 23 days due to multiple organ failure. A detailed analysis representing all the critical laboratory and clinical findings of these HCMV infected SJS/TEN patients have been provided in Table 5 .

\section{Immunological parameters in patients with HCMV associated SJS/TEN}

A detailed serum cytokine analysis of the HCMV infected SJS/ TEN patients revealed a low IFN $\gamma$ (Mean- $0.59 \mathrm{IU} / \mathrm{ml}$ ) and low TNF a (Mean-14.95 pg/ml) levels relative to that in HIV patients with drug induced SJS (Mean $-0.97 \mathrm{IU} / \mathrm{ml}$ for IFN $\gamma$ and $27.8 \mathrm{pg} / \mathrm{ml}$ for TNF $\alpha$ ) but higher than that of HCMV coinfected HIV Patients without SJS (Mean -HIV ${ }^{+} \mathrm{HCMV}-0.36 \mathrm{IU} / \mathrm{ml}$ for IFN $\gamma$ and $11.9 \mathrm{pg} / \mathrm{ml}$ for TNF $\alpha$ ) . There was no significant difference in the IL6 and IL8 levels among the HCMV infected SJS/TEN patients (Mean- $18.7 \mathrm{pg} / \mathrm{ml}$ and $39 \mathrm{pg} /$ $\mathrm{ml}$, respectively) and HIV patients with drug induced SJS (mean- 18.9 $\mathrm{pg} / \mathrm{ml}$ and $39.3 \mathrm{pg} / \mathrm{ml}$, respectively). The IL12 level was considerably lower in case of HCMV infected SJS/TEN patients (Mean-37 pg/ml) compared to that of HIV patients with drug induced SJS (Mean- 41.3 $\mathrm{pg} / \mathrm{ml}$ ) but almost similar to that of HCMV co-infected HIV Patients 
Citation: Chatterjee A, Thakur I, Ansari S, Chatterjee RP, Sarkar R, et al. (2017) A Comparative Insight into the Incidence of Steven Johnson Syndrome/ Toxic Epidermal Necrolyis among the Immunocompromized Patient Populace of Eastern India with a Distinctive Emphasis on the Possible Association of Human Cytomegalovirus. J AIDS Clin Res 8: 706. doi: 10.4172/2155-6113.1000706

Page 8 of 9

\begin{tabular}{|c|c|c|c|c|}
\hline Variables & Patient 1 & Patient 2 & Patient 3 & Patient4 \\
\hline Age & 56 & 59 & 71 & 65 \\
\hline SJS/TEN & SJS & SJS & SJS & TEN \\
\hline Gender & Male & Female & Male & Male \\
\hline Associated internal organ diseases & $\begin{array}{l}\text { Hepatitis, Retinitis, } \\
\text { GI pain }\end{array}$ & $\begin{array}{c}\text { Retinitis, } \\
\text { neurological impairment }\end{array}$ & $\begin{array}{l}\text { Arrhythmia, Pulmonary } \\
\text { hypertension }\end{array}$ & Hepatitis, Retinitis \\
\hline HIV viral load & $8.3 \times 10^{4}$ & $6.36 \times 10^{4}$ & $9.39 \times 10^{4}$ & $9.78 \times 10^{4}$ \\
\hline CD4+ T cell count & 76 & 71 & 34 & 23 \\
\hline HCMV viral load & $8.2 \times 10^{5}$ & $7.12 \times 10^{5}$ & $7.32 \times 10^{6}$ & $9.8 \times 10^{6}$ \\
\hline WBC count & $1.3 \times 10^{4}$ & $9.9 \times 10^{3}$ & $9.2 \times 10^{3}$ & $8.9 \times 10^{3}$ \\
\hline Time from symptom onset (Days) & 9 & 11 & 8 & 13 \\
\hline BSA involved & $<10 \%$ & $<20 \%$ & $<30 \%$ & $>30 \%$ \\
\hline Nikolsky's sign & Present & Present & Present & Absent \\
\hline Mucosal involvement & $\begin{array}{c}\text { High } \\
\text { Oral and genital }\end{array}$ & $\begin{array}{c}\text { High } \\
\text { Oral, Optic } \quad \text { and genital }\end{array}$ & $\begin{array}{c}\text { High } \\
\text { Optic and genital }\end{array}$ & $\begin{array}{c}\text { Very high } \\
\text { Oral, optic and genital }\end{array}$ \\
\hline Haemorrhagic manifestations & Absent & Present & Present & Absent \\
\hline Duration of hospital stay (Days) & 21 & 17 & 19 & 23 \\
\hline Hematocrit (\%) & 62 & 58 & 71 & 65 \\
\hline Creatinine (mg/dl) & 1.8 & 2.1 & 2.6 & 1.1 \\
\hline Albumin (gm/L) & 19.6 & 21.5 & 24.7 & 18.3 \\
\hline Urea (mg/dl) & 18.9 & 23.7 & 22.2 & 19.6 \\
\hline SGPT (IU/L) & 91.6 & 119.3 & 97.1 & 123.7 \\
\hline SGOT (IU/L) & 85.7 & 103.6 & 89.8 & 115.2 \\
\hline
\end{tabular}

Table 5: Clinical features and laboratory findings of the SJS or TEN cases associated with acute HCMV infection.

\begin{tabular}{|c|c|c|c|c|c|}
\hline & \multirow[b]{2}{*}{$\begin{array}{l}\text { IFN } \gamma \\
\text { (IU/mI) }\end{array}$} & \multicolumn{2}{|c|}{$\begin{array}{l}\text { Cytokine analysis } \\
\text { profile }\end{array}$} & \multirow[b]{2}{*}{$\begin{array}{c}\text { IL-8 } \\
(p g / m l)\end{array}$} & \multirow[b]{2}{*}{$\begin{array}{l}\mathrm{IL}-12 \\
(\mathrm{pg} / \mathrm{ml})\end{array}$} \\
\hline & & $\begin{array}{l}\mathrm{TNF} \alpha \\
(\mathrm{pg} / \mathrm{ml})\end{array}$ & $\begin{array}{c}\mathrm{IL}-6 \\
(\mathrm{pg} / \mathrm{ml})\end{array}$ & & \\
\hline *HIV ${ }^{+}$ & 0.75 & 18.3 & 14.6 & 30.8 & 32.5 \\
\hline *HIV+HCMV & 0.36 & 11.9 & 17.8 & 35.5 & 37.8 \\
\hline *HIV+SJS & 0.97 & 27.8 & 18.9 & 39.3 & 41.3 \\
\hline Patient 1 & 0.65 & 18.7 & 18.1 & 40.1 & 36.4 \\
\hline Patient 2 & 0.61 & 17.5 & 16.8 & 37.7 & 39.9 \\
\hline Patient 3 & 0.54 & 12.2 & 20.6 & 38.4 & 37.2 \\
\hline Patient 4 & 0.59 & 11.4 & 19.4 & 39.8 & 34.8 \\
\hline
\end{tabular}

HIV+- HIV seropositive patient

HIV+HCMV- HIV seropositive patient coinfected with HCMV

HIV+SJS- HIV seropositive patient with Steven-Johnson syndrome

${ }^{*}$ At least 3 patients were chosen for each case and the mean value calculated.

Table 6: Analysis of the serum cytokine levels of the differentially infected patient.

without SJS (Mean- $37.8 \mathrm{pg} / \mathrm{ml}$ ). The detailed cytokine analysis profile has been provided in Table 6 .

\section{HCMV PCR detection in tissue samples of patients with HCMV associated SJS/TEN}

Punch biopsies were taken from lesional and perilesional skin. PCR was found to be positive for HCMV DNA in all 4 skin biopsies.

\section{Discussion}

This study is the first of its kind from India in which we have characterized and compared all the relevant clinical and physiological attributes related to the development of SJS and TEN in HIV seropositive patients. It is important to recognize the clinical and etiologic characteristics of the mucocutaneous eruption at early stage due to the associated high mortality rate [16]. The most common precipitating drug causing SJS/TEN in this study was found to be neviraprine followed by allopurinol. Mycobacterium was found to

be the most common pathogen attributed to the severity of SIS/ TEN followed by EBV, HCMV and others. Patient age, the area of mucocutaneous involvement and involvement of multiple internal organs has been identified as significant factors associated with patient mortality. The mortality rate in this present study was found to be $24.1 \%$. With early recognition of the cause of this condition and selected treatments, the mortality rate could be reduced. Improved understanding of clinical presentation and risk factors should help physicians to improve the care of high-risk individuals at an earlier stage. Corticosteroid use significantly increased the chance of survival among these patients. The results of the present study revealed a lower number of cases of mortality than predicted by SCORTEN score. Disease involvement of multiple organs was common among all the patients. There was no significant difference in SCORTEN score between survival and non-survival groups. The frequency of incidence of kidney disease and ocular dysfunction was found to be significantly higher among the SJS patients whereas that of hepatitis and pulmonary dysfunction were higher among the TEN patients. 4 patients out of 29 were linked to HCMV infection as the probable trigger behind SJS/ TEN development. In detailed and thorough analysis revealed that probable time of onset of HCMV infection precedes or correlates SIS/ TEN development. Analysis of cytokine markers gave a new direction towards detection and diagnosis of HCMV associated SJS/TEN patients as the measured serum cytokine levels significantly differed from the other group of patients tested. Immuno histochemistry images confirmed acute involvement of HCMV and epidermal degeneration. The skin is the initial site of HCMV involvement (visceral disease) and may provide the first clue to systemic infection [17]. A wide spectrum of cutaneous lesions associated with HCMV infection has been reported, including purpura, morbilliform eruptions, lesions, papular eruptions, verrucous and vesiculobullous lesions, ulcerations etc. but to date no case of SJS has been related to this infectious agent [18]. However, a relationship between viral infections and the simultaneous or subsequent development of drug-induced hypersensitivity has been 
Citation: Chatterjee A, Thakur I, Ansari S, Chatterjee RP, Sarkar R, et al. (2017) A Comparative Insight into the Incidence of Steven Johnson Syndrome/ Toxic Epidermal Necrolyis among the Immunocompromized Patient Populace of Eastern India with a Distinctive Emphasis on the Possible Association of Human Cytomegalovirus. J AIDS Clin Res 8: 706. doi: 10.4172/2155-6113.1000706

observed in a number of clinical situations, while the full cascade of events leading from viral infections to the development of this exfoliative situation in human's remains poorly understood $[19,20]$. In this study we have tried to establish a possible association between HCMV and SJS/TEN suggested possibly by a temporal clinical relationship. Temporal relationship and clinical features do suggest that HCMV infection with acute viral replication can predispose the immunocompromized patients towards TEN-SJS [21,22]. Although without a thorough understanding of the underlying mechanisms involved, it is difficult to establish a direct causal link between HCMV infection and mucocutaneous hypersensitivity. The herpesvirus family is a likely candidate to be able to greatly influence immune responses because herpesviruses can induce and maintain a potent memory $\mathrm{T}$ cell response due to their common properties of ubiquitous prevalence in human populations and the capacity to grow in lymphoid cells $[23,24]$. Specific viral infections have been shown to increase CD95 (Fas) and/ or Fas Ligand expression and increase sensitivity to Fas/ Fas Liganddependent apoptosis.

\section{Limitations and Conclusion}

The most significant hurdle in this observational study was the severely low frequency of SJS/TEN development among HIV infected immunocompromized population. During the three years' time span of this study after screening thousands of HIV seropositive cases, we came across only 29 cases of SJS/TEN involvement in HIV seropositive patients and out of them only $4(13.7 \%)$ were found to have a direct association with HCMV coinfection. Thus in terms of the small size, short time scale and the selective type of the study population selected, an advanced statistically efficient epidemiological data set could not be generated. Another drawback was that the study was designed to include only hospitalized patients. This may not provide the full evaluation of the condition in terms of both quality and quantity of management in general. Despite the limitations stated, this study with its exhaustive data analysis is sure to provide a considerable impact in the health and medicine sector of a developing country like India.

\section{Funding}

This work has been performed by the intramural grant provided by Indian Council of Medical Research, New Delhi, India.

\section{References}

1. Mockenhaupt M (2011) The current understanding of Stevens-Johnson syndrome and toxic epidermal necrolysis. Expert Rev Clin Immunol 7: 803-813.

2. Bastuji-Garin S, Rzany B, Stern RS, Shear NH, Naldi L (1993) Clinical classification of cases of toxic epidermal necrolysis, Stevens-Johnson syndrome and erythema multiforme. Arch Dermatol 129: 92-96.

3. Gerull R, Nelle M, Schaible T (2011) Toxic epidermal necrolysis and Stevens Johnson syndrome: A review. Crit Care Med 39: 1521-1532.

4. Letko E, Papaliodis DN, Papaliodis GN, Daoud YJ, Ahmed AR, et al. (2005) Stevens-Johnson syndrome and toxic epidermal necrolysis: A review of the literature. Ann Allergy Asthma Immunol 94: 436-438.

5. Singh H, Kachhap VK, Kumar BN, Nayak K (2011) Nevirapine induced StevensJohnson syndrome in an HIV infected patient. Indian J Pharmacol 43: 84-86.

6. Ting HC, Adam BA (1985) Stevens-Johnson syndrome: A review of 34 cases. Int J Dermatol 24: 587-591.
7. Pereira FA, Mudgil AV, Rosmarin DM (2007) Toxic epidermal necrolysis. J Am Acad Dermatol 56: 181-200.

8. Paik S, Sen S, Era N, Saha B, Tripathi SK (2016) Fatal Nevirapine-induced toxic epidermal necrolysis in a HIV infected patient. J Clin Diagn Res 10: FD03FD06.

9. Sassolas B, Haddad C, Mockenhaupt M, Dunant A, Liss Y, et al. (2010) ALDEN algorithm for assessment of drug causality in Stevens Johnsons syndrome and toxic epidermal necrolysis: Comparison with case control analysis. Nature 88: 60-67.

10. Jhaj R, Uppal R, Malhotra S, Bhargava VK (1999) Cutaneous adverse reactions in in-patients in a tertiary care hospital. Indian J Dermatol Venereol Leprol 65: 14-17.

11. Sanmarkan AD, Sori T, Thappa DM, Jaisankar TJ (2011) Retrospective analysis of Stevens-Johnsons syndrome and toxic epidermal necrolysis over a period of 10 years. Indian J Dermatol 56: 25-29.

12. (2014) Nevirapine induced toxic epidermal necrolysis and non-Hodgkin lymphoma in a human immunodeficiency virus positive patient. Indian Dermatol Online J 5: 179-181.

13. Mockenhaupt M, Viboud C, Dunant A, Naldi L, Halevy S, et al. (2008) Stevens Johnson's syndrome and toxic epidermal necrolysis: Assessment of medication risks with emphasis on recently marked drugs - The Euro SCAR study. J Invest Dermatol 128: 35-44

14. Fournier S, Bastuji Garin S, Mentec H, Revuz J, Roujeau JC (1995) Toxic epidermal necrolysis associated with Mycoplasma pneumoniae infection. Eur J Clin Microbiol Infect Dis 14: 558-559.

15. Tanaka A, Nakano M, Tani M, Kira M, Katayama I, et al. (2013) Adult case of Stevens Johnson syndrome possibly induced by Chlamydophila pneumoniae infection with severe involvement of bronchial epithelium resulting in constructive respiratory disorder. J Dermatol 40: 492-494.

16. Drago F, Aragone MG, Lugani C, Rebora A (2000) Cytomegalovirus infection in normal and immunocompromised humans. A review. Dermatology 200: 189195.

17. Lee T, Bae YJ, Park SK, Park HJ, Kim SH, et al. (2010) Severe pneumonia caused by combined infection with Pneumocystis jiroveci, parainfluenza virus type 3, cytomegalovirus and Aspergillus fumigatus in a patient with StevensJohnson syndrome/toxic epidermal necrolysis. Acta Derm Venereol 90: 625629.

18. Khalaf D, Toema B, Dabbour N, Jehani F (2011) Toxic epidermal necrolysis associated with severe cytomegalovirus infection in a patient on regular hemodialysis. Mediterr J Hematol Infect Dis 3: e2011004.

19. Cruz MJ, Mota A, Baudrier T, Gil-da-Costa MJ, Azevedo F (2010) StevensJohnson syndrome associated with cytomegalovirus infection in a child with ependymoma. J Dermatol Case Rep 4: 11-14.

20. Choi YL, Kim JA, Jang KT, Kim DS, Kim WS, et al. (2006) Characteristics of cutaneous cytomegalovirus infection in non-acquired immune deficiency syndrome, immunocompromised patients. Br J Dermatol 155: 977-982.

21. Chan HL, Stern RS, Arndt KA, Langlois J, Jick SS, et al. (1990) The incidence of erythema multiforme, Stevens-Johnson syndrome and toxic epidermal necrolysis. Arch Dermatol 126: 43-47.

22. Garcia-Doval I, LeCleach L, Bocquet H, Otero XL, Roujeau JC (2000) Toxic epidermal necrolysis and Stevens-Johnson syndrome: Does early withdrawal of causative drugs decrease the risk of death? Arch Dermatol 136: 323-327.

23. Torres MJ, Mayorga C, Blanca M (2009) Nonimmediate allergic reactions induced by drugs: pathogenesis and diagnostic tests. J Investig Allergol Clin Immunol 19: 80-90.

24. Bay A, Akdeniz N, Calka O, Kösem M, Faik Oner A, et al. (2005) Primary varicella infection associated with Stevens-Johnson syndrome in a Turkish child. J Dermatol 32: 745-750. 